\title{
STATUS EPILEPTICUS IN CHILDREN CLINICO ETIOLOGICAL PROFILE AND OUTCOME
}

\author{
S. Gunasekhara Raju1, S. Somasekhar Rao ${ }^{2}$
}

${ }^{1}$ Assistant Professor, Department of Paediatrics, RIMS, Srikakulam, Andhra Pradesh. ${ }^{2}$ Assistant Professor, Department of Paediatrics, RIMS, Srikakulam, Andhra Pradesh.

\begin{abstract}
Status epilepticus is a common condition in acute medical care. Approximately 4.5 million SE events occur worldwide every year.SE in children differs from adult SE in aspects of epidemiology, pathophysiology and clinical presentations, which justifies a separate analysis. The incidence in children is about 18-20/100,000 children/year and distribution of etiologies is markedly age-dependent: Febrile and acute symptomatic convulsive SE is most common in children aged less than 2 years, whereas cryptogenic/idiopathic and remote symptomatic etiologies are more common in older children. A prospective study where 46 children, admitted in Pediatric Intensive Care Unit with seizures lasting $>30$ minutes in King George Hospital, Visakhapatnam, were studied over a period from 2012 June to 2013 oct. These patients were evaluated for their clinical presentation, laboratory parameters, treatment profile and immediate outcome. As mortality is higher in younger age groups and status with acute symptomatic etiology, there is a need to aggressively treat these groups. As the longer a seizure continues the harder it is to be controlled and as both the mortality and sequelae were found to be significantly lesser in the patients who attained good seizure control within 1 hour of presentation to the hospital.
\end{abstract}

KEYWORDS: Status Epilepticus, Febrile Children, Ferizures.

HOW TO CITE THIS ARTICLE: S. Gunasekhara Raju, S. Somasekhar Rao. "Status Epilepticus in Children Clinico Etiological Profile and Outcome". Journal of Evolution of Medical and Dental Sciences 2015; Vol. 4, Issue 92, November 16; Page: 15762-15770, DOI: $10.14260 /$ jemds/2015/2278.

INTRODUCTION: Status epilepticus (SE) is a major medical and neurological emergency. The first Adescription of SE in the medical literature was in a Babylonian text from the first millennium BC. Status epilepticus is a common condition in acute medical care. Approximately 4.5 million SE events occur worldwide every year. ${ }^{1} \mathrm{SE}$ in children differs from adult SE in aspects of epidemiology, pathophysiology and clinical presentations, which justifies a separate analysis. The incidence in children is about 18-20/100,000 children/year and distribution of aetiologies is markedly age-dependent: Febrile and acute symptomatic convulsive SE is most common in children aged less than 2 years, whereas cryptogenic/idiopathic and remote symptomatic aetiologies are more common in older children. Approximately $70 \%$ of SE occurs in children less than one year and $75 \%$ in less than three years of age. ${ }^{2}$ the first episode most commonly occurs around 2.5years after initial diagnosis. ${ }^{3}$

Hauser reported that up to $70 \%$ of children who have epilepsy that begins before the age of 1 year experience an episode of SE, also it has been observed that $20 \%$ of individuals with epilepsy will have an episode of SE within 5 years of the initial diagnosis. SE before initial diagnosis of epilepsy, young age at onset and symptomatic etiology independently influence the risk. The numbers of studies that are annually published on SE have steadily increased during the last few years. But despite the socioeconomic burden of $\mathrm{SE}$ and the interest among the medical community, many

Financial or Other, Competing Interest: None.

Submission 26-10-2015, Peer Review 27-10-2015,

Acceptance 05-11-2015, Published 14-11-2015.

Corresponding Author:

Dr. S. Somasekhar Rao,

Assistant Professor,

RIMS, Sri kakulam, Andhra Pradesh.

E-mail: somasekharseepana@gmail.com

DOI:10.14260/jemds/2015/2278. questions concerning its pathogenesis, management and outcome remain unanswered.

Status epilepticus requires immediate and vigorous management and at times poses a therapeutic challenge to the treating physician. If not managed promptly, it may result in significant neuromorbidity and mortality.4,5 Though systematic approach and prompt treatment have reduced the mortality and morbidity associated with SE over the years, it is still associated with significant morbidity and mortality

Mortality rates Children have a far lower mortality rate than do adults, with the exception of those in the first year of life. Age, etiology, and duration correlate directly with mortality. Multiple studies confirm the lower mortality rate in most children following adequate emergency treatment as high as $30 \%$ have been reported in overall studies.

MATERIALS AND METHODS: A prospective study where 46 children, admitted in Pediatric Intensive Care Unit with seizures lasting $>30$ minutes in King George Hospital, Visakhapatnam, were studied over a period from 2012 june to 2013 oct. These patients were evaluated for their clinical presentation, laboratory parameters, treatment profile and immediate outcome.

\section{Inclusion Criteria for the Study:}

1. Patients fulfilling the definition of SE as per International Classification of Epileptic Seizure as 'Continuous seizure activity lasting for more than 30 minutes of continuous seizure activity or two or more sequential seizures without full recovery of consciousness between seizures.

2. Patients in the age group of 2 months to 12 years.

Exclusion Criteria for the Study:

1. Patients with seizure activity lasting for less than 30 minutes. 
2. Patients aged less than 2 month and more than 12 years

3. Patients where the duration of seizure activity could not be documented with or without regaining consciousness or patients whose case records had no time specification.

4. Patients in whom proper diagnosis could not be established (in cases where the duration from time of admission to death was too short for evaluation).

\section{Definitions:}

- Seizures were classified as per International League Against Epilepsy Group Definitions

- History of epilepsy is defined as two or more unprovoked seizures in the past whether on treatment or not.

- Initial seizure control was based on seizure control by drugs at the time of first contact with the emergency services.

- Good response was defined as seizure activity controlled with antiepileptic drugs (AED) within 60 minutes of contact with hospital and initiation of therapy.

- SE was defined as refractory, if the duration for control of seizure activity was $>\mathrm{lhr}$, even after adequate treatment with two or more drugs (benzodiazepines, and phenytoin and/or phenobarbitone),

- Mortality was defined as death occurring in PICU during the course of treatment of SE irrespective of whether it was controlled or not.

Study Method: The details were based on information provided by parents, time of onset of seizures, their presentation to emergency department, documentation by the doctor on duty in PICU, so as to be very clear about the duration of seizure, as this was the most important criteria for definition. The information was carefully recorded in the proforma. A detailed physical examination was done with the consent of the parents.Investigations were done according to clinicalsuggestions Complete blood counts, Urine analysis, Blood sugar, Blood Urea Serum Creatinine, Serum electrolytes, Serum Calcium, Liver function tests, Peripheral Smear, QBC for Malarial parasite, Blood culture, Widal test, CSF analysis, Cheat X-ray, Mantoux test ,ECG, Electrencephalography, CT scan brain, MRI Brain, Blood gas analysis.

Diagnosis: Diagnoses were recorded for all patients according to the International Classificationof Diseases, tenth revision.

Treatment: Immediate resuscitative measures were taken, Antiepileptic drugs for short term and long term control, as per the protocol of management of status epilepticus,were instituted and specific treatment modality was started and changed according to patient's course in the hospital.

Follow Up: Patients were evaluated daily till discharge/death. The degree of sequelae developed was assess.

\section{OBSERVATION AND RESULTS}

Age and Sex Distribution: For the purpose of the study the patients were divided in the age groups of 2 months to $2 \mathrm{yrs}$, $>2$ yrs to 5 yrs and $>5$ yrs. The maximum number of cases was seen in the age group of less than 2 yrs. The mean age of presentation was $44.9+36.6$ months and 33 cases $(72 \%)$ were below the age of $5 y$ rs. There was a statistically significant association between the occurrence of status in the age group of less than 5 years $(\mathrm{p}=<0.05)$. The number of males was 27 , constituting $58.7 \%$ and the number of females was 19 constituting $41.3 \%$. There was a slight male preponderance, however it was not statistically significant $(\mathrm{p}=>0.05)$.

\begin{tabular}{|c|c|c|c|}
\hline AGE GROUP & MALE & FEMALE & TOTAL (\%) \\
\hline 2 months -2 & 11 & 7 & $18(39.17 \%)$ \\
\hline $2-5$ yr. & 7 & 8 & $15(32.6 .3 \%)$ \\
\hline$>5$ yr. & 9 & 4 & $13(28 \%)$ \\
\hline Total (\%) & $\mathbf{2 7}(\mathbf{5 8 . 7 \% )}$ & $\mathbf{1 9}(\mathbf{4 1 . 3 \% )}$ & $\mathbf{4 6 ( 1 0 0 \% )}$ \\
\hline
\end{tabular}

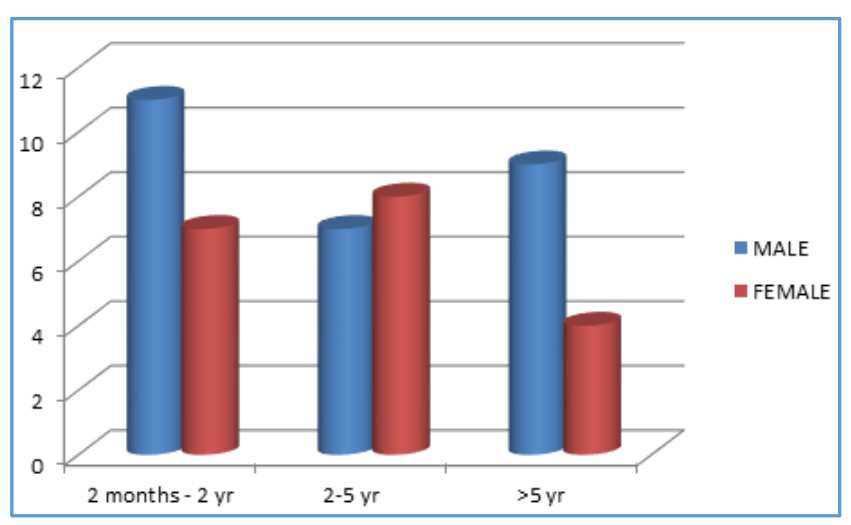

Time Lag of Presentation: The time taken from the onset of seizures to presentation to our hospital was recorded; the average time of presentation was $4.256 \pm 3.59$ hours. Twenty seven patients had received some type of treatment before arriving to the pediatric casualty. The average time of presentation to any kind of medical services was $3.09+2.74$ hours. The reason for this gross delay was mainly ignorance about the seriousness of the disease, lack of nearby medical services, lack of transport facilities and poor financial status.

For the purpose of the study the duration of presentation to the hospital was divided into groups as follows:

\begin{tabular}{|c|c|}
\hline $\begin{array}{c}\text { Duration of seizure at time of } \\
\text { presentation to KGH }\end{array}$ & $\begin{array}{c}\text { No. of } \\
\text { cases }\end{array}$ \\
\hline$<\mathrm{hr}$ & $11(24 \%)$ \\
\hline $1 \mathrm{hr}-3 \mathrm{hr}$ & $12(26 \%)$ \\
\hline $3 \mathrm{hr}-6 \mathrm{hr}$ & $15(33 \%)$ \\
\hline$>6 \mathrm{hr}$ & $8(17.5 \%)$ \\
\hline Total & $\mathbf{4 6 ( 1 0 0 \% )}$ \\
\hline
\end{tabular}




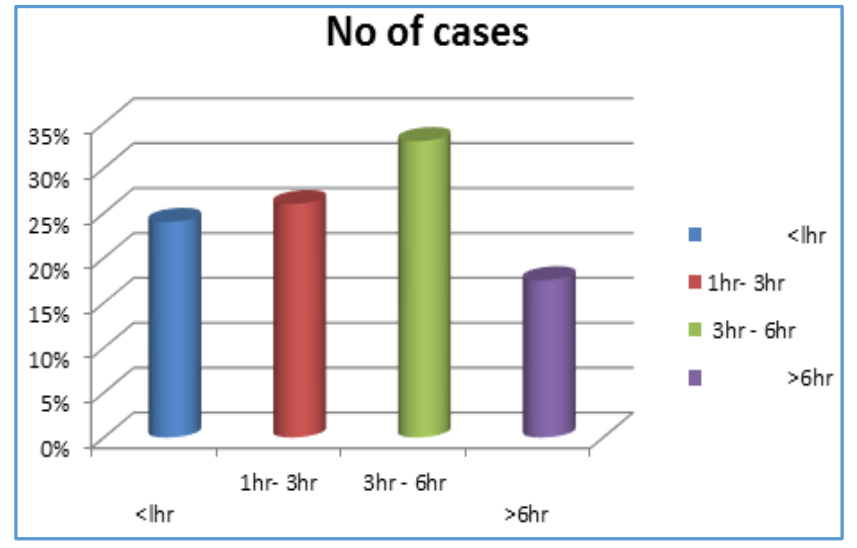

TYPE OF SEIZURES: The most common type of seizure was generalised tonic clonic type. Other varieties seen were complex partial seizures with or without automatisms, generalised tonic seizures and complex partial seizures with secondary generalisation. 2 cases of simple partial status were also seen.

\begin{tabular}{|c|c|}
\hline Type of Seizure & $\begin{array}{c}\text { No. of Cases } \\
\text { (a) }\end{array}$ \\
\hline Generalized tonic-clonic seizures (GTCS) & $25(54.3 \%)$ \\
\hline Generalized tonic seizure (GTS) & $3(6.5 \%)$ \\
\hline Complex partial seizures (CPS) & $16(34.8 \%)$ \\
\hline Simple partial seizures (SPS) & $2(4.4 \%)$ \\
\hline Total & $46(100 \%)$ \\
\hline
\end{tabular}

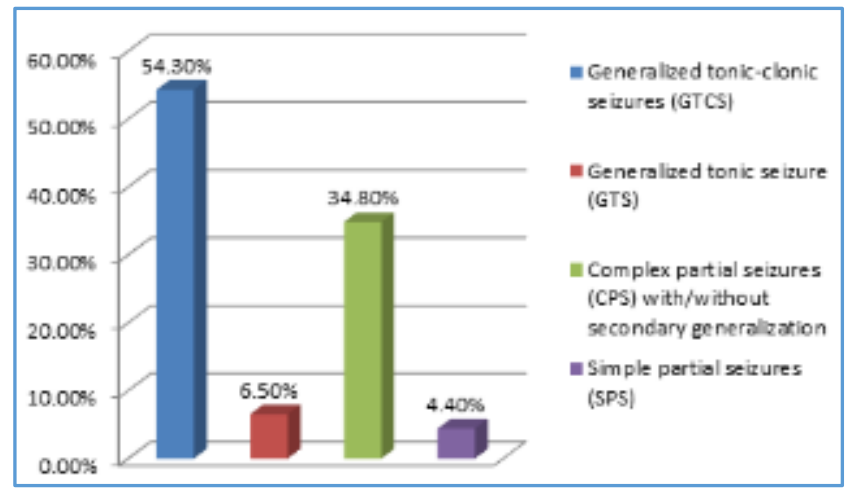

PRESENCE OF FEVER: Out of the 46 cases, 35 (76\%) had fever and $11(24 \%)$ did not have fever at the time of presentation.

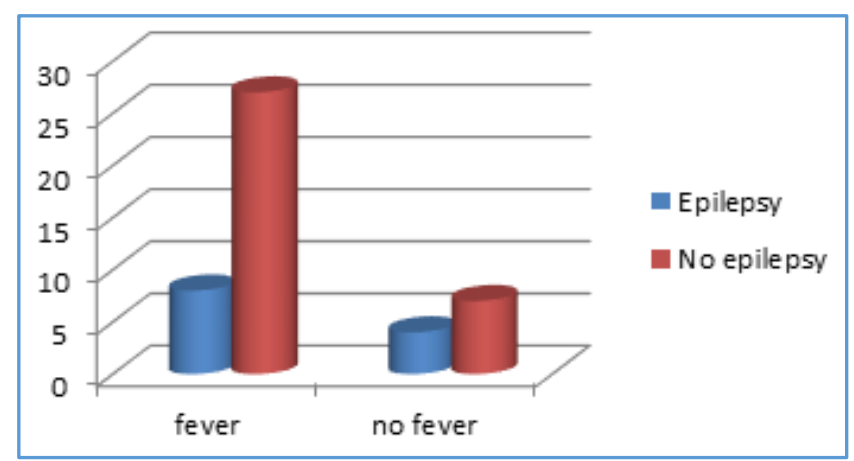

Previous History of Seizures: There were 12(26\%) cases with a previous history of seizures, of these 4 had had a previous history of status epiiepticus. 3 cases were finally diagnosed to have Idiopathic epilepsy and 9 cases were those with underlying neurological deficit.

The pattern of antiepileptic drug administration for epileptic patients was as follows:

\begin{tabular}{|c|c|}
\hline Pattern of AED & No. of Cases \\
\hline Withdrawal & $2(17 \%)$ \\
\hline Irregular & $7(58 \%)$ \\
\hline Regular & $3(25 \%)$ \\
\hline Total & $\mathbf{1 2 ( 1 0 0 \% )}$ \\
\hline
\end{tabular}

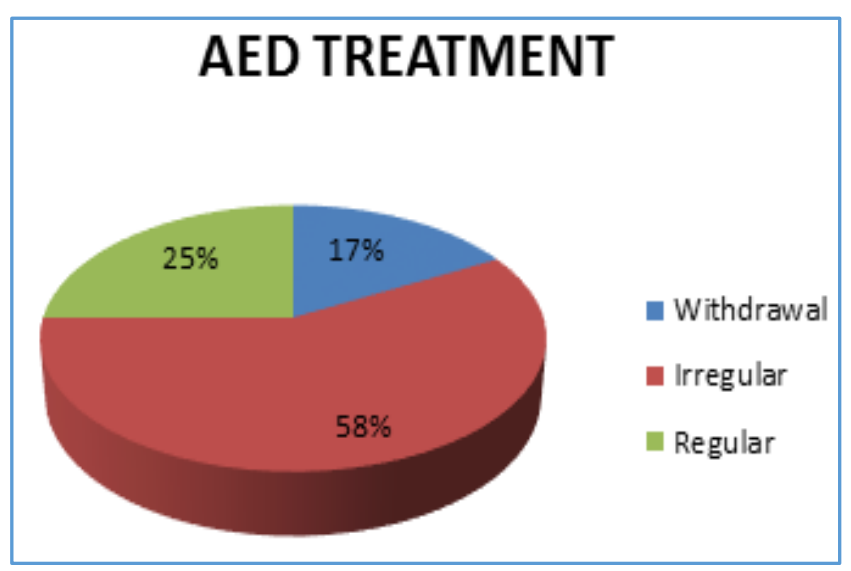

8 patients $(67 \%)$ of the 12 had presented with fever secondary to upper respiratory tract infections, gastroenteritis and viral fevers. All three cases on regular treatment had intercurrent infections.

Birth Weight, Birth Asphyxia and Developemental Delay: Among patients with history of developmental delay, the birth weight and details of birth were carefully recorded. There were 12 patients with developmental delay, of which $5(42 \%)$ patients had history of birth asphyxia and 4 also had history of neonatal seizures. Of these 7 were adequate for birth weight and 5 had a low birth weight. On the whole $9(75 \%)$ cases out of the 12 had some incriminating factor in the neonatal period whereas $3(25 \%)$ had an apparently normal neonatal period.

Socioeconomic Status: The socioeconomic status of the patients was assessed using the modified Kuppuswamy scale. They were divided into Classes - I, II, III, IV, V based on the education, occupation and per capita income.

The Data was as Follows:

\begin{tabular}{|c|c|}
\hline Socioeconomic status & No. of cases \\
\hline Class I \&II(Upper \& upper middle) & 0 \\
\hline Class III (Lower middle) & $12(26 \%)$ \\
\hline Class IV (Upper lower) & $29(63 \%)$ \\
\hline Class V (Lower) & $5(11 \%)$ \\
\hline
\end{tabular}

The time lag of presentation to the medical services was analysed with the socioeconomic status of the patient, using a Chi-square test, to look for an association between them. 


\begin{tabular}{|c|c|c|}
\hline \multirow{2}{*}{$\begin{array}{c}\text { Time lag of } \\
\text { Presentation }\end{array}$} & \multicolumn{2}{|c|}{ Socioeconomic Status } \\
\cline { 2 - 3 } & Lower & Middle and Upper \\
\hline$<1 \mathrm{hr}$ & 9 & 7 \\
\hline$>1-3 \mathrm{hr}$ & 7 & 4 \\
\hline$>3-6 \mathrm{hr}$ & 11 & 1 \\
\hline$>6 \mathrm{hr}$ & 7 & 0 \\
\hline
\end{tabular}

There was statistically significant association $(\mathrm{p}<0.0001)$ between the socioeconomic status and the duration of seizure prior to presentation to the hospital. Patients from lower classes (Kuppuswamy class IV and V) presented later than those from higher classes.

NUTRITION: The nutritional status was categorised as per the IAP classification for malnutrition.

\begin{tabular}{|c|c|}
\hline Nutritional Status & No. of Cases \\
\hline Normal $(>80 \%$ of expected) & $12(26 \%)$ \\
\hline Grade I $(>70 \%$ to $<80 \%$ of expected) & $10(21.7 \%)$ \\
\hline Grade II $(>60 \%$ to $<70 \%$ of expected) & $18(39 \%)$ \\
\hline Grade III $(>50 \%$ to $<60 \%$ of expected) & $4(8.7 \%)$ \\
\hline Grade IV ( $<50 \%$ of expected) & $2(4.6 \%)$ \\
\hline Total & $46(100 \%)$ \\
\hline
\end{tabular}

Only $12(26 \%)$ out of the 46 had the expected weight for age, all others were below the expected.

OTHER CLINICAL SIGNS (At the time of presentation)

\begin{tabular}{|c|c|}
\hline - Glasgow Coma Scale & \\
\hline$<6$ & 20 \\
\hline $6-12$ & 23 \\
\hline$>12$ & 2 \\
\hline \multicolumn{2}{|l|}{ - Posture } \\
\hline Decorticate & $4(8.7 \%)$ \\
\hline Decerebrate & $8(17.4 \%)$ \\
\hline Normal/Others & $34(73.9 \%)$ \\
\hline \multicolumn{2}{|l|}{ - Blood pressure } \\
\hline Normal & $30(65.2 \%)$ \\
\hline Low & $6(13 \%)$ \\
\hline High & $10(21.8 \%)$ \\
\hline \multicolumn{2}{|l|}{ - Cranial nerve palsy } \\
\hline Present & $7(15.2 \%)$ \\
\hline Absent & $39(84.8 \%)$ \\
\hline \multicolumn{2}{|l|}{ - Tone } \\
\hline Increased & $18(39.1 \%)$ \\
\hline Decreased & $11(23.9 \%)$ \\
\hline Normal & $17(37 \%)$ \\
\hline \multicolumn{2}{|l|}{ - Motor deficit } \\
\hline Diffuse signs & $19(76.1 \%)$ \\
\hline Hemiparesis & $8(17.4 \%)$ \\
\hline Monoparesis & $1(2.1 \%)$ \\
\hline Paraparesis & $2(4.3 \%)$ \\
\hline \multicolumn{2}{|l|}{ - Meningeal signs } \\
\hline Present & $12(26.1 \%)$ \\
\hline Absent & $34(73.9 \%)$ \\
\hline \multicolumn{2}{|c|}{ - Raised Intracranial tension } \\
\hline Present & $14(30.4 \%)$ \\
\hline Absent & $32(69.6 \%)$ \\
\hline \multicolumn{2}{|c|}{ - Splenomegaly \pm hepatomegaly } \\
\hline Present & $9(19.6 \%)$ \\
\hline Absent & $37(80.4 \%)$ \\
\hline
\end{tabular}

- Most of the cases had a GCS of less than 12 on presentation to the hospital Only 2(4.3\%)) had a GCS more than 12 and these were cases of simple partial seizure.

- The blood pressure of most of the patients, $65.2 \%$, was within the normal range for age and sex. $6(13 \%)$ had low values which was mostly seen in children less than 5 yrs of age and longer duration of seizures. Patients with high blood pressure were those with symptoms with raised intracranial pressure.

- $7(15.2 \%)$ had cranial nerve palsies and these were mostly cases of TB meningitis. One of the cases was that of Rasmussen's encephalitis with associated monoplegia.

- The most common motor deficit was seen in the form of diffuse signs like exaggerated or diminished tendon reflexes, plantar extensor and loss of superficial reflexes. It was seen in 19 cases (76.1\%). The next most common was hemiparesis which was seen mostly in cases with TB meningitis. Seven cases had a prior motor deficit, 3 had spastic quadriparesis, 2 had spastic hemiparesis and 2 had spastic paraparesis.

- Signs of meningeal irritation were present in 12 cases (26.1\%), which were cases of TB meningitis, pyomeningitis or viral meningoencephalitis.

- Raised intracranial tension features were seen 14(30.4\%), which were seen mainly in cases with TB meningitis, pyomeningitis, viral meningoencephalitis or cerebral malaria.

- Abdominal findings in the form of hepatomegaly and/or splenomegaly were present in $19.6 \%$ of cases, all of whom had malaria.

\section{INVESTIGATIONS:}

- CSF ANALYSIS: A lumbar puncture was done in 28 cases as per clinical suspicion. 7 cases showed a tuberculous picture, 4 showed a viral meningitis picture, 1 had a pyomeningitis picture and the remaining was normal study.

- CT SCAN / MRI SCAN: Imaging studies as indicated were done on 43 patients, 23 cases had features specific for their disease, 6 had features of diffuse cortical atrophy, 2 had features of diffuse cerebral edema, 2 had features of both diffuse cortical atrophy and specific features of the disease and the remaining (1 leases $25.6 \%$ ) were normal study.

- INTERICTAL EEG: Since the facility of continuous EEG monitoring was not available and interictal EEG was done. This was done in 21 cases with suspicion of epilepsy. Only 5 demonstrated an epileptic foci, while most of them, 11 (52.3\%), had features of diffuse cerebral dysfunction. The others had a normal EEG.

- OTHERS: 9 cases were QBC positive for malarial parasite and only 2 demonstrated a mantoux positivity.

Etiology: Based on etiology the cases were broadly divided into three categories: Acute symptomatic status, remote symptomatic status and Idiopathic status. Acute symptomatic status consists of status due to any CNS infection, electrolyte disorders, toxic exogenous, acute anoxic insult, trauma or 
metabolic disorders etc. Remote symptomatic status consists of status due to any neonatal insult especially hypoxicischemic, non-progressive encephalopathy of obscure origin, CNS malformations and progressive encephalopathies. Idiopathic status consists of status not appearing to be associated with any cause of brain damage. It may be febrile, representing the extreme of the spectrum of febrile convulsions, or afebrile.

\section{The following were the etiologies seen:}

\section{Acute symptomatic - 25 cases $(54.3 \%)$}

Pyomeningitis

$\begin{array}{ll}- & 1 \\ - & 2 \\ - & 1 \\ - & 4 \\ - & 9(19.6 \%) \\ - & 8(17.4 \%)\end{array}$

Neurocysticercosis $\quad-\quad 2$

Cortical vein thrombosis $\quad-\quad 1$

Viral meningoencephalitis - 4

Cerebral malaria $\quad$ - $9(19.6 \%)$

CNS tuberculosis — - $8(17.4 \%)$

The most common acute symptomatic causes were CNS tuberculosis and cerebral malaria consisting about. 68\% of the total acute symptomatic causes.

$\begin{array}{lc}\text { 2. Remote symptomatic } & \text { 16 cases (34.8\%) } \\ \text {-Nonprogressive } & 7 \\ \text {-cerebral palsy } & 1 \\ \text {-epilepsy } & 1 \\ \text {-cerebral venousmalformations } & 1 \\ \text {-bilateral occipital gliosis } & 1 \\ \text {-periventricular leucomalacia } & 2 \\ \text {-previous intracranial bleed } & 1 \\ \text {-Avm of left occipital lobe } & \\ \text { Progressive } & 1 \\ \text {-metachromatic leucodystrophy } & 1 \\ \text {-Rasmussen encephalitis } & \\ & \mathbf{5} \\ \text { 3. Idiopathic } & 4 \\ \text {-Epilepsy } & 1 \\ \text {-Febrile status } & \end{array}$

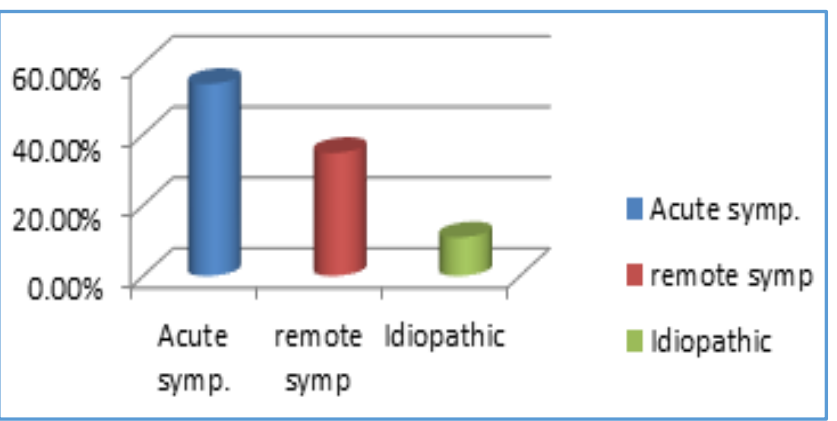

On the whole the most common cause for status was acute symptomatic causes followed by remote symptomatic causes and least common were idiopathic epilepsy and febrile status.

TREATMENT AND RESPONSE: Sixteen patients presented directly to the pediatric casualty, they were not given any treatment outside. Three cases developed status while on treatment for other causes in the PICU. Twenty-seven patients had received some type of treatment before arriving to the Pediatric casualty. The most common treatment given was Inj. Diazepam (18 cases), 5 were given a second drug in the form of Phenytoin or Phenobarbitone and for 7 cases the details were not known.

The time lapse for treatment was categorised into drug administration within 45 minutes of onset of seizures and after 45 minutes of onset of seizure. Among the 27 cases referred from outside 21 fell in the former category, whereas only 6 were given within 45 minutes. The patients presenting directly to the casualty also had the majority (16 cases) receiving treatment beyond 45 minutes. 3 cases who were within the hospital when status developed received treatment in $<45$ minutes.

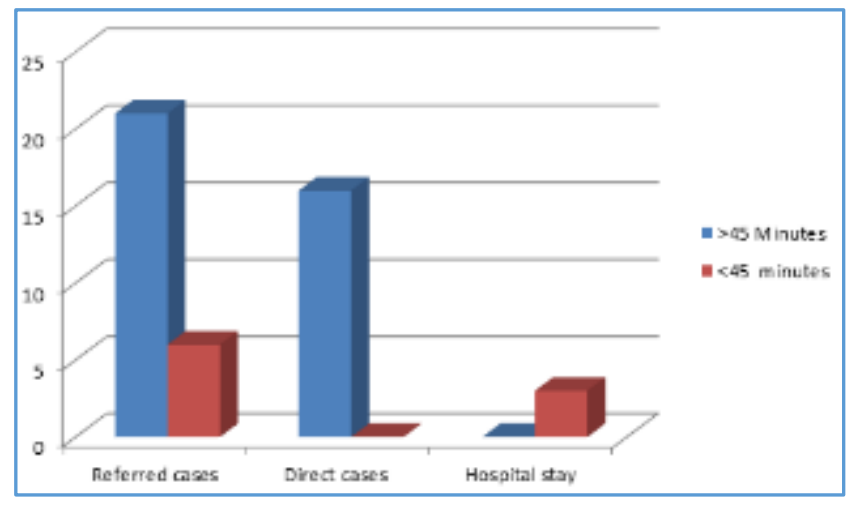

After admission the cases were management as per the status management protocol as mentioned earlier. When seizures were controlled within 1 hour of hospital admission and adequate treatment, it was considered to be good response. When the seizures were not controlled within 1 hour of hospital admission and adequate treatment with two drugs it was considered to be refractory status Thirty-eight (38) out of the 46 cases responded to the antiepileptic drug administration, 7 patients died and 1 case of Rasmussen's encephalitis did not respond to any antiepileptics.

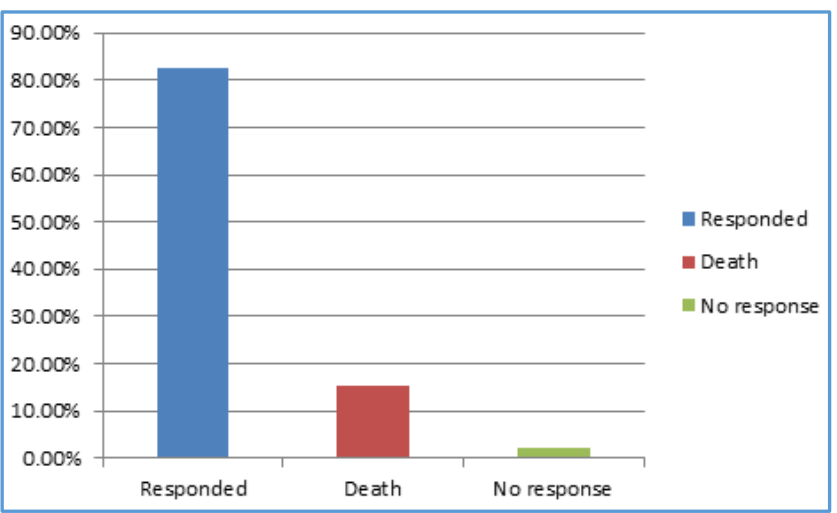

Among the patients who survived, 17 were good responders and 22 were Refractory. The majority hence were refractory.

\begin{tabular}{|c|c|}
\hline Type of response & No. of cases (\%) \\
\hline Good response & $17(43.6 \%)$ \\
\hline Refractory & $22(56.4 \%)$ \\
\hline Total & $\mathbf{3 9}(\mathbf{1 0 0} \%)$ \\
\hline
\end{tabular}

On trying to find an association between the duration of seizure before acquiring any form of treatment with response 
to treatment, it was found that there was a significant association $(\mathrm{p}=0.0112)$. The total duration of seizure activity from onset to response was calculated. The average duration of seizure activity was $10.72 \pm 12.03$ hours. Only 3 cases had seizure duration of less than 1 hour, while the remaining had a duration of $>1$ hour.

Most of the cases (71.8\%) were controlled by either 2 drugs or three drugs, consisting of short term antiepileptics, phenytoin and/or phenobarbitone. $28.2 \%$ required 4 drugs consisting of short term antiepileptics, phenytoin, phenobarbitone and midazolam. One case of Rasmussen's encephalitis could not attain control even after multiple drug administration.

The number of drugs required for control was as follows:

\begin{tabular}{|c|c|}
\hline No. of Drugs & No» of Cases (\%) \\
\hline 2 drugs & $17(37 \%)$ \\
\hline 3 drugs & $16(34.8 \%)$ \\
\hline 4 drugs & $12(28.2 \%)$ \\
\hline Total & $\mathbf{4 5 ( 1 0 0 \% )}$ \\
\hline
\end{tabular}

Hospital Stay: The average duration of hospital stay was $8.152174 \pm 5.56963$ days.

Outcome: The outcome was divided into no sequelae, sequelae in the form of motor or mental handicap and death. Sequelae were defined as newly acquired motor deficit, aphasia, persistently vegetative state, loss of developmental milestones, and mental handicap.

\begin{tabular}{|c|c|}
\hline Outcome & No* of cases (\%) \\
\hline No sequelae & $17(37 \%)$ \\
\hline Sequelae & $22(47.8 \%)$ \\
\hline Death & $7(15.2 \%)$ \\
\hline Total & $46(100 \%)$ \\
\hline
\end{tabular}

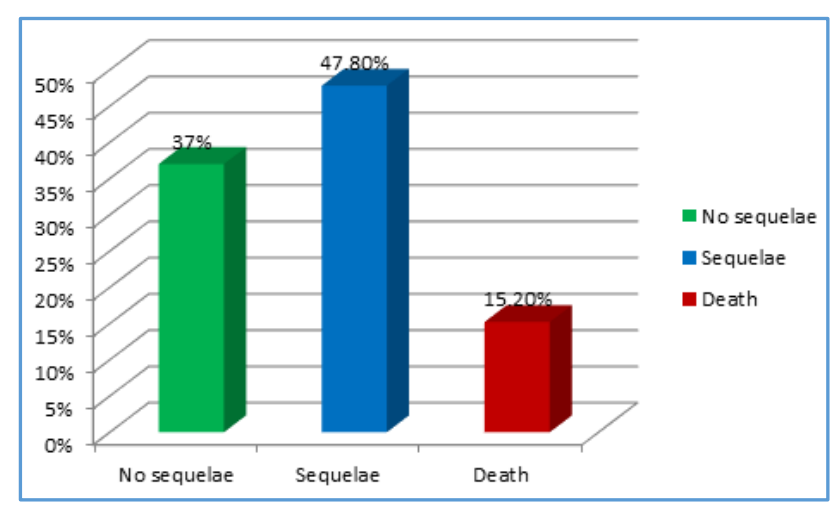

had a poor outcome, in the form of either sequelae (47.8\%) or death $(15.2 \%)$. The sequelae were in the form of motor deficit, speech impairment and cognitive disabilities.

Out of the 46 patients presented with status, there were 12 children with prior neurological deficit, in this worsening of the symptoms was assessed based on history and examination at discharge. Seven (58.3\%) of these patients developed sequelae, $3(25 \%)$ had no new deficit and $2(16.7 \%)$ died during the episode of status.

Out of the 34 patients with no prior deficit, 14(41.2\%) were normal at discharge, 15(44.1\%) developed sequelae and $5(14.7 \%)$ died. Among the patients who died $72 \%$ died within 24 hours, 14\%(1) died within 48 hours and 14\% died after $48 \mathrm{hrs}$.

\section{DISCUSSION:}

Age and Sex Distribution: The mean age of presentation in the present study was $44.9 \pm 36.6$ months and $72 \%$ were below the age of 5 yrs. There was a statistically significant association between the occurrence of status in the age group of less than 5 years $(p=<0.05)$. This was comparable with the study by Veena Kalra et al, 20056, wherein the mean age of presentation was $56.6+46.5$ months and $56 \%$ of the cases were below the age of 5 yrs. The present study however affected patients were of a slightly younger age than that seen in the Veena Kalra et al study.

Similar findings were seen in Delorenzo RJ et al, $1996{ }^{7}$ Hesdorffer DC et al, $1998 .{ }^{8}$ and Hauser WA et al, 1990.9 The reason for this predominance of $\mathrm{SE}$ in younger children is not known. Probably, mechanisms for control of seizure activity are fragile in younger children and may get disrupted with minimal abnormalities in neurofunction. There was a male preponderance but no significant association between status and the gender of the patient, as was also in Veena Kalra et al., 2005.

Lag Time of Presentation and Duration of Seizure: The average duration of seizures before presenting to any kind of medical services was $3.09 \pm 2.74$ hours which was comparable but slightly higher to that seen In a Malawi study by Ahmed S et al, 2006, wherein the average duration of seizures before hospital treatment was 2 hours. The average total duration of seizures seen was $10.72 \pm 12.03$ hours. Similar findings were reported in a Kenyan study by Edwards T et al 2008. ${ }^{10}$ where the status lasted for many hours.

This similarity is due to both the studies being from developing countries, where the resources are poor and ample facilities for transport and medical services are not widely available. There was statistically significant association $(\mathrm{p}<0.0001)$ between the socioeconomic status and the duration of seizure prior to presentation to the hospital. Patients from lower classes (Kuppuswamy class IV and V) presented later than those from higher classes. This association reflects the financial constraints, illiteracy and ignorance among the normal population.

Type of Seizure: The most common form of seizures was generalized tonic-clonic consisting 54.3\%), which was similar to other studies like the study by Barzegar $\mathrm{M}$ et al, 2007 and the Kenyan study by Edwards $\mathrm{T}$ et al, 2008.10 Congdon and Forsythe et al, 1980.11 and Aicardi and Cheverie et al, 1970.12 also report similar findings.

Previous History of Seizures: Thirty-four patients (74\%) presented without prior history of seizures. Twelve cases presented with a prior history of seizures, of which 7 cases (58\%) were poorly controlled. The percentage of patients 
presenting as the first episode was higher in comparison to the study by Veena Kalra et al, $2005 .^{6}$ which had $53.3 \%$ cases presenting as the first episode. However, Shinnar et al, $1990 .{ }^{13}$ recorded only $12 \%$ cases as presenting as status without any prior history.

This difference may be due to the differences in etiology, as is explained later. In cases which were eventually diagnosed as epilepsy, status epilepticus lead to the diagnosis in $25 \%$ which was slightly lower than that seen by Hersdorffer et al, $1998^{8}$ (30\%). Also in these cases 36\%o had unprovoked status epilepticus, which was higher than that seen in Hersdoffer et al, 1998 (18\%), the reason to which might be a poorer control or irregular treatment seen in patients with epilepsy in this study.

Etiology: The following table depicts the causes of status epilepticus in various studies:

\begin{tabular}{|c|c|c|c|c|c|}
\hline \multirow{2}{*}{ ETIOLOGY } & \multicolumn{5}{|c|}{ Name of the Study } \\
\cline { 2 - 6 } & $\begin{array}{c}\text { Aicardi } \\
\text { and } \\
\text { Chevrie.12.12 } \\
\mathbf{1 9 7 0} \\
\mathbf{( N = 2 3 9 )}\end{array}$ & $\begin{array}{c}\text { Phillips } \\
\text { and } \\
\text { Shanahan.2. } \\
\mathbf{1 9 8 9} \\
\mathbf{1}=\mathbf{1 9 3})\end{array}$ & $\begin{array}{c}\text { Veena } \\
\text { Kalra } \\
\text { et.6 } \\
\text { Al.5.7 } \\
\mathbf{2 0 0 5} \\
\mathbf{( N = 3 0 )}\end{array}$ & $\begin{array}{c}\text { Kwong } \\
\text { KL } \\
\text { etal.14 } \\
\mathbf{2 0 0 8} \\
\mathbf{( N = 3 7 )}\end{array}$ & $\begin{array}{c}\text { Present } \\
\text { Study } \\
\mathbf{2 0 0 8} \\
\mathbf{( N = 4 6 )}\end{array}$ \\
\hline Acute & $26 \%$ & $44 \%$ & $40 \%$ & $60 \%$ & $54 \%$ \\
\hline Remote & $21 \%$ & $11 \%$ & $47 \%$ & $13 \%$ & $35 \%$ \\
\hline Idiopathic & $28 \%$ & $32 \%$ & $3 \%$ & $11 \%$ & $9 \%$ \\
\hline Febrile & $25 \%$ & $14 \%$ & $10 \%$ & $5 \%$ & $2 \%$ \\
\hline
\end{tabular}

According to literature, acute symptomatic causes are becoming more common in recent series and febrile status is still the most common form. This is the case with studies by Erikksson KJ et al, 1997, Shinnar et al, 1992 etc. In our study, acute symptomatic was the most common form and febrile the least common. This trend was similarly seen in other newer studies shown in the table like Veena Kalra et al and Kwong KL atal. ${ }^{14}$ This was probably due to the higher occurrence of acute symptomatic causes and better control of febrile seizures in recent times.

TREATMENT RESPONSE: As mentioned before treatment response was divided into good response and refractory. In the present study $43.6 \%$ of cases showed a good response and $56.4 \%$ cases were refractory. The refractory cases was higher than in most studies like Veena Kalra et al (40\%), Mayer Stephan et al, $2002 .{ }^{15}(30 \%)$, and an Iranian study by Barzegar M et al, 2007 (40.7\%). This may be explained by the average greater time lag before presentation to emergency services.

As shown by the study by Shinnar S et al, 2001, the longer the seizure lasts, the less likely it is to stop in the next few minutes. On trying to find an association between the duration of seizure before acquiring any form of treatment with response to treatment, it was found that there was a significant association $(p=0.0112)$ showing a progressive increase in the duration for control of seizure with thatof increase in the time lag of presentation to medical services.
Outcome: The mortality in the present study was $15 \%$ (approx.). This was comparable to some of the studies as shown. The mortality of some of the studies was as follows: Veena Kalra et al, 2005. ${ }^{6}$ - 30\% Knowng Kl et al, 1995. ${ }^{14}$ - 11\% Longroscino et al, 1997 - 1 \% Hersdorffer et al, 1984.16 - 21\% Delorenzo RJ et al, 1996.17 - 22\%. The mortality in this study was lower than that found in the study by Veena Kalra et al. This could be explained by the higher percentage of sequelae seen in the present study. The percentage of sequelae in our study was $47.8 \%$.

\section{The sequelae in some of the other studies are:}

$15 \%$ in Eriksson et al, 1997.18

$36 \%$ in Aicardi J et al, 1970.12

$17.5 \%$ in Maytal J et al., 1989.19

The higher sequelae in present study can be explained by the prolonged duration of seizure activity as explained later.

\section{OUTCOME AND RISK FACTORS}

Age and Outcome: The mortality was significantly higher ( $p=0.0365$ ) in the age group of $<36$ months, in the present study. In the study by Veena Kalra et al there was a greater mortality in the same age group but it was not significant. (44.4\% Vs 23.8\%, p=0.487) Significant association was seen in Delorenzo et al, 1992 and Chevrie and Aicardi, 1977. Age had minimal association in the study by Dunn et al., 1988'.

There was no significant $(p=1.000)$ increase in the sequelae in children of younger age group. Significant association in age group $<12$ months was seen in the Kenyan study by Sadarangani M et ah, 2008.20

Gender and Outcome: No significant association was found with the sex of the patient and mortality $(\mathrm{P}=0.6823)$. This was the case with other studies like, Delorenzo et al, $1992^{21}$, Sadarangani M et al, $2008^{20}$ and AH Akbar et ah, 2005. No significant association was found between sequelae and the gender of the patient. However, a possibility of having more sequelae in the female sex was seen in the study by Chevrie and Aicardi, 1978.

Type of Onset of Seizure and Outcome: The association between any type of seizure and mortality was not significant. (12.5\% Vs $21.7 \%$, p=0.545). This was contrary to the study by Sadarangani M et al., 2008. ${ }^{20}$ where there was a significant association between focal onset of seizures and mortality.

Time Lag for Presentation to Medical Ser Vices and Outcome: The time lag for presentation to medical services was divided into $>45$ minutes and $<45$ minutes. 6 patients (16\%) with lag time for treatment of $>45$ minutes duration died when compared to 1 patient (11\%) with lag time for treatment $<45$ minutes. The association of patients with longer lag time, dying more, however was not significant $(\mathrm{p}=1.000)$. Similar findings were seen in the study by Veena Kalra et al. However in our study there was a significant association between shorter lag time to treatment and no sequelae, $(p=0.0125)$. 
Total Seizure Duration and Outcome: All the 7 cases $(19.4 \%)$ that died had seizure duration of more than 2 hour. None of the cases with a seizure duration of $<2$ hours died. A higher cut off was taken because of a longer duration of seizure before presentation to the hospital. There was however no statistical significance found $(\mathrm{p}=0.3159)$. Similar findings were seen in the study by Mayer Stephan A et al., 2002, which is explained later.

However, the study by Veena Kalra et al there was a significant association between a seizure duration of $>45$ minutes and mortality $(\mathrm{p}=0.0001)$. Similar associations were found in studies like, Delorenzo et al, 1992 Dunn et aL, 1988. ${ }^{22}$ But there was significant association found between longer duration and seizure duration and higher incidence of sequelae $(\mathrm{p}=0.0001)$. This was as seen in the study by Mayer Stephan A et al., 2002.

Response to Treatment and Outcome: Both the mortality and sequelae were found to be significantly lesser in the patients who attained good seizure control within 1hour of presentation to the hospital. The corresponding $\mathrm{p}$ values were 0.0362 and $<0.0001$. All 7 who died had refractory status and 20 of the 22 cases of refractory SE had sequelae. In the study by Mayer Stephan A et al 2002.15 it was found that RSE was associated with prolonged hospital length of stay $(\mathrm{P}<.001)$ and more frequent functional deterioration at discharge $(\mathrm{P}=0.02)$.

There was however no significant increase in the mortality. The study by Veena Kalra et al., also showed similar findings as our study where 6 cases with response to treatment more than or equal to 1 hour died in comparison to 3 who responded $<1$ hour. This was however statistically not significant $(\mathrm{p}=0.068)$.

Etiology and Outcome: Five out of the 25 cases of acute symptomatic cause died (Mortality $=20 \%$ ), whereas 2 out of the remaining 19 died (Mortality $=10.5 \%$ ). The mortality was definitely higher in the acute symptomatic group however it was not statistically significant $(p=0.4285)$. Significant association between etiology and outcome was seen in various studies like, Delorenzo et al, $1992 .{ }^{21}$ Dunn et al, 1988.22 and Ali Akbar et al, 2005 Prolonged febrile seizures had the best and symptomatic SE the worst, outcome, in most of the studies.

In our study cerebral malaria was significantly associated with a good outcome that is no sequelae $(p=0.0016)$. Seven of the 9 cases of cerebral malaria had a good outcome, 7 out of the remaining 37 had a good outcome. This was similar to that found in a Kenyan study by Sadarangani $\mathrm{M}$ et al, 200820; where positive malaria slide was associated with low mortality.

In our study, none of the malaria cases died, but the association of malaria with a low mortality was not found to be statistically significant.In our study, $40 \%$ of patients of Idiopathic/ febrile cause had sequelae whereas $58 \%$ with other etiologies had sequelae. This was though not statistically significant $(\mathrm{p}=0.636)$. Idiopathic or febrile status was significantly associated with lesser sequelae in studies by Dunn et ah, and Ali Akbar et al. The relatively higher percentage of sequelae may again be again due to the delay in treatment.

\section{SUMMARY:}

- The study consisted of 46 patients, 27 male and 19 female. The mean age of presentation was $44.9+36.6$ months and 34 cases $(74 \%)$ were below the age of $5 y$ rs, which was similar to other studies.

- The average duration of seizures before presenting to any kind of medical services was $3.09 \pm 2.74$ hours and there was statistically significant association $(\mathrm{p}=0.0375)$ between the socioeconomic status and the duration of seizure prior to presentation to the hospital. Both these results reflect the poor economic resources, education and awareness standards of the parents and the poor infrastructure of the developing countries.

- The most common form was generalized tonic-clonic seizures as seen in various studies.

- There were a higher number of cases presenting as status without a prior history of seizures. $36 \%$ had unprovoked status epilepticus, which was higher than seen in other studies, the reason to which might be a poorer control or irregular treatment seen in patients with epilepsy in this study.

- In our study, acute symptomatic was the most common form and febrile the least common. This was in contrary to the literature which describes febrile status as the most common form. However, there were many studies showing similar trends. The difference seen may be due to the higher prevalence of infective (Acute Symptomatic) illnesses in the current population and good control of febrile seizures.

- $\quad 43.6 \%$ o of cases showed a good response and $56.4 \%$ cases were refractory. The refractory cases were higher than in most studies. This can be explained by the average greater time lag before presentation to emergency services, and the significant association $(\mathrm{p}=0.0112)$ seen as, the longer the seizure lasts, the less likely it is to stop in the next few minutes.

- The mortality in the present study was $15 \%$. The percentage of sequelae in our study was $47.8 \%$. The relatively lower mortality when compared to higher average total duration may be due to the fact that longer duration of seizures were associated with higher incidence of sequelae $(p=0.0001)$ than a higher mortality $(p=0.3159)$ as was seen in this study.

- The mortality was significantly higher $(p=0.0365)$ in the age group of $<36$ months, in the present study as in other studies.

- No significant association was found with the sex of the patient and mortality ( $p=0.6823$ ) and sequelae, as in other studies.

- There was no association found between a greater time lag for treatment and mortality however there was a significant association between greater lag time to treatment and sequelae, $(\mathrm{p}=0.0125)$.

- Both the mortality and sequelae were found to be significantly lesser in the patients who attained good seizure control within 1 hour of presentation to the hospital. 
- $\quad$ Five out of the 25 cases of acute symptomatic cause died (Mortality=20\%), whereas 2 out of the remaining 19 died (Mortality $=10.5 \%$ ). The mortality was definitely higher in the acute symptomatic group however it was not statistically significant $(\mathrm{p}=0.4285)$.

- In our study, $40 \%$ of patients of idiopathic/ febrile cause had sequelae whereas $58 \%$ with other etiologies had sequelae. This was though not statistically significant $(\mathrm{p}=0.636)$. Idiopathic or febrile status was significantly associated with lesser sequelae in various studies.

\section{CONCLUSIONS:}

- Status epilepticus is the most common neuroemergency and still remains to be associated with a high mortality and morbidity.

- As mortality is higher in younger age groups and status with acute symptomatic etiology, there is a need to aggressively treat these groups.

- As the longer a seizure continues the harder it is to be controlled and as both the mortality and sequelae were found to be significantly lesser in the patients who attained good seizure control within 1 hour of presentation to the hospital, facilities for early transport and easily reachable medical services have to be improved and steps have to be taken to increase the awareness about the detrimental effects of prolonged seizures, and about the good outcome if treated early.

\section{REFERENCES:}

1. DeLorenzo RJ. Epidemiology and clinical presentation of status epilepticus. Adv Neurol 2006; 97:199-215.

2. Phillips SA, Shanahan RJ. 1989. Etiology and mortality of status epilepticus in children- a recent update. Arch Neurol 46:74-76.

3. Berg AT, Shinnar S, Testa FM, Levy SR, Frobish D, Smith $\mathrm{SN}$, et al. Status epilepticus after the initial diagnosis of epilepsy in children Neurology 2004;63;1027-34.

4. Singhi S, Singhi P, Dass R.: Status epilepticus: Emergency management.

Indian JPaediatric 2003; 70 (Special suppl 1) S I - 22.

5. Hanhan UA, Fiallos MK, Orlowski JP. Status epilepticus. Pediatr Clin North Am 2001;48:683-94.

6. Gulati S, Kalra V, Sridhar MR. Status epilepticus in Indian children in a tertiary care center.

Indian J Pediatr 2005;72:105-8.

7. DeLorenzo RJ, Hauser WA, Towne AR et al. A prospective, population-based epidemiological study of status epilepticus in Richmond, Virginia. Neurology 1996;46:1029-1035.
8. Hesdorffer DC, Logroscino G, Cascino G, Annegers JF, Hauser WA. Risk of unprovoked seizure after acute symptomatic seizure: Effect of status epilepticus. Ann Neurol 1998;44:908-12.

9. Hauser WA. Status epilepticus: epidemiologic considerations. Neurology 1990;40:S9-S13.

10. Edwards, T; Scott, AG; Munyoki, G. Active convulsive epilepsy in a rural district of Kenya: a study of prevalence and possible risk factors. Lancet Neurol. 2008;7:50-56.

11. Congdon P, Forsyth W. 1980. Intravenous clonazepam in treatment of status epilepticus in children. Epilepsia 21:97-102.

12. Aicardi J, Chevrie JJ. Convulsive status epilepticus in infants and children. A study of 239 cases. Epilepsia 1970; 11:187-97.

13. Shinnar S, Berg AT, Moshe SL, et al. 1990. Risk of recurrence following a first unprovoked seizure in childhood: A prospective study.

Pediatrics 85: 1076-1085.

14. Kwong KL, Lee SL, Yung A, Wong VC. Status epilepticus in 37Chinese children: Aetiology and outcome. JPaediatr Child Health 1995;31:395-8.

15. Mayer Stephan A., Claassen Jan ; Lokin Johnny ; Mendelsohn Felicia; Dennis Lyle J.; Fitzsimmons BrianFred; Refractory status epilepticus: Frequency, risk factors, and impact on outcome.

Archives of neurology, 2002, vol. 59, No:2, 205-210.

16. Hesdorffer DC, Logroscino G, Cascino G, Annegers JF, Hauser WA. Incidence of status epilepticus in Rochester, Minnesota. 1965-1984. Neurology 1998;50:735-741.

17. DeLorenzo RJ, Hauser WA, Towne AR et al. A prospective, population-based epidemiologic study of status epilepticus in Richmond, Virginia. Neurology 1996; 46: 1029-1035

18. Eriksson KJ, Koivikko MJ.Status epilepticus in children: aetiology, treatment, and outcome. 1997; 8:11-24.

19. Maytal J, Shinnar S, Moshe SL, Alvarez LA. Low morbidity and mortality of status epilepticus in children. Pediatrics 1989;83:323-31.

20. Sadarangani M., Seaton C, Scott J., Newton C, Incidence and outcome of convulsive status epilepticus in Kenyan children: a cohort study.

Lancet Neurol 2008 February; 7(2): 145-150.

21. Lorenzo RJ, Towne AR, Pellock JM and Ko D. Status epilepticus in children, adults and the elderly. Epilepsia 1992; 33: S15-S25.

22. Dunn DW, Status epilepticus in children: etiology, clinical features, and outcome. Journal of Child Neurology*, Vol. 3, No. 3, 167-173 (1988). 